\title{
Validation of Part-Filter Analysis to Estimate Smokers' Mouth Level Exposure to 'Tar' and Nicotine*
}

\author{
by \\ Krishna Prasad ${ }^{1}$, Madeleine Ashley ${ }^{1}$, and Mike Dixon ${ }^{2}$ \\ ${ }^{1}$ British American Tobacco, Group Research and Development, Southampton SO15 8TL, UK, \\ ${ }^{2}$ Dixon Consultancy, Kilve, Somerset, UK,
}

\section{SUMMARY}

Part-filter analysis is a method used to assess mouth level exposure (MLE) of cigarette smokers to mainstream smoke constituents. We assessed the robustness of part-filter analysis to compare MLE to nicotine and 'tar' between smoker populations and during calibration. Three groups of subjects smoked two batches of the same brand of 1-mg ISO tar yield Hungarian cigarettes three times each. Eighteen calibration curves were produced with three operators using three smoking machines. Within each batch of cigarettes, MLE did not differ significantly between the three smoker groups or after repeated smoking within groups. MLE was marginally higher for cigarettes from Batch 1 than Batch 2. No significant differences were found between the slopes and intercepts of the calibration curves produced using different smoking machines and operators. Part-filter analysis offers a repeatable means of estimating smokers' 'tar' and nicotine MLE in large-scale studies in their everyday smoking environments. [Beitr. Tabakforsch. Int. 26 (2015) 261-268]

\section{ZUSAMMENFASSUNG}

Die Teil-Filter-Analyse ist eine Methode zur Bestimmung der Exposition im Mundraum (mouth level exposure, MLE) von Zigarettenrauchern gegenüber Bestandteilen des Hauptstromrauchs. Wir haben die Robustheit der TeilFilter-Methode untersucht und die MLE gegenüber Nikotin und 'Teer' bei verschiedenen Raucherpopulationen und während der Kalibrierung verglichen. Drei Gruppen von Probanden rauchten jeweils drei Mal Zigaretten derselben ungarischen Marke mit 1-mg Teerausbeute nach ISO aus zwei Chargen. Mit drei Bedienern und drei Rauchmaschinen wurden 18 Kalibrierkurven erstellt. In keiner Charge der Zigaretten unterschied sich die MLE signifikant, weder zwischen den drei Rauchergruppen noch nach wiederholtem Rauchen innerhalb der Gruppen. Die MLE fiel für die Zigarettencharge 1 marginal höher aus als für Charge 2. Es wurden keine signifikanten Unterschiede zwischen den Steigungen und Achsenabschnitten der mit verschiedenen Rauchmaschinen und Bedienern erstellten Kalibrierkurven ermittelt. Die Teil-Filter-Analyse bietet in großangelegten Studien und unter normalen Rauchbedingungen eine reproduzierbare Methode für die Schätzung der 'Teer' - und Nikotinexposition im Mundraum bei Rauchern. [Beitr. Tabakforsch. Int. 26 (2015) 261-268]

\section{RESUME}

L'analyse à filtre partiel est une méthode utilisée pour évaluer l'exposition des tissus buccaux (mouth level exposure, MLE) des fumeurs de cigarettes aux constituants de la fumée principale. Nous avons évalué la capacité de l'analyse à filtre partiel à effectuer une comparaison de l'exposition des tissus buccaux à la nicotine et au goudron chez des populations de fumeurs et lors d'un étalonnage. A trois reprises, trois groupes de sujets ont fumé deux lots de la même marque de cigarettes hongroises avec un rendement en goudron de 1-mg ISO. Dix-huit courbes 
d'étalonnage furent tracées par trois opérateurs utilisant trois machines à fumer. Pour chaque lot de cigarettes, aucune différence significative de l'exposition des tissus buccaux ne fut observée ni parmi les trois groupes de fumeurs ni après répétition de la consommation au sein des groupes. L'exposition des tissus buccaux lors de la consommation $\mathrm{du}$ premier lot de cigarettes fut marginalement supérieure à l'exposition observée pour le deuxième lot. Aucune différence significative ne fut observée entre les pentes et les points d'intersection des courbes d'étalonnage produites à l'aide des différentes machines à fumer par les différents opérateurs. L'analyse à filtre partiel propose une approche reproductible permettant d'estimer l'exposition des tissus buccaux des fumeurs à la nicotine et au goudron dans le cadre d'études à grande échelle dans des environnements normaux de tabagisme. [Beitr. Tabakforsch. Int. 26 (2015) 261-268]

KEYWORDS: Cigarette; smoke; smoker; 'tar'; nicotine; mouth level exposure

\section{INTRODUCTION}

Measurement of the exposure of smokers to mainstream smoke constituents provides a means of assessing the effect of product modifications on mainstream cigarette smoke emissions. Methods to determine mouth level exposure (MLE) to mainstream smoke constituents based on the analysis of $10 \mathrm{~mm}$ mouth-end sections of spent cigarette filters have been described previously (1-15). The technique involves the determination of nicotine, solanesol or 'tar' retained in cigarette filters versus the yields in smoke constituents of cigarettes smoked by machine for calibration, and the analysis of the nicotine, solanesol or 'tar' content of smokers' spent cigarette filters to provide estimates of their MLE to smoke constituents. In our study, smokers' MLE to nicotine was assessed with the linear regression equation obtained by plotting the mainstream smoke nicotine yield versus the tip nicotine data obtained during calibration smoking and the measured smoker tip nicotine values. Similarly, MLE to 'tar' was obtained with the linear regression equation derived by plotting mainstream smoke nicotine free dry particulate matter (i.e., 'tar' yield), versus tip extract UV absorbance obtained during calibration smoking and the measured smoker tip extract UV absorbance data.

The technique has been used in a number of studies that had various objectives, including the comparison of MLE to 'tar' and nicotine in different smoker groups smoking their own products in different markets (16) or within a market (17-19) and with groups of smokers switching from higher to lower 'tar' and nicotine yield cigarettes (3). The methodology has also been used to assess the effect of the Scottish ban on smoking in public places on smokers' MLE to 'tar' and nicotine (20) and the effect of the introduction of the cigarette low ignition propensity regulations in Canada (21). MLE obtained using part-filter analysis has been shown to correlate significantly with biomarkers of exposure over a wide range of smoke exposures (2).

The part-filter analysis method typically uses spent filters obtained from individuals smoking in their normal environments. Thus, one advantage of the method is that the behaviour of the smokers is not influenced by the use of equipment to monitor puffing topography or invasive and disruptive biofluid sampling procedures. Smokers are typically unsupervised during studies and this study was conducted to investigate whether smoking by three different groups of smokers, repeated smoking (three different occasions), and smoking of cigarettes from two different production batches would influence part-filter analysis outcomes in the estimation of smokers' MLE to nicotine and 'tar'. The part-filter analysis method is based on filtration characteristics of smoker-supplied filters against those achieved during machine smoking over a wide range of puffing regimes. It is important that consistent calibration curves are obtained, and the accuracy of the method should not be influenced by the type of smoking machine used or the operator of the machine. Therefore the intermediate precision (22) due to different smoking machines $(n=3)$, operators $(n=3)$ and repeats of calibrations $(n=2)$ in the construction of the calibration curves was investigated.

\section{METHODS}

\section{Study cigarettes}

A 1-mg ISO 'tar' yield commercial product was used in the study. It had a market share of approximately $1 \%$, thus enabling the recruitment of a sufficient number of smokers to ensure matching of demographic characteristics. The study cigarettes were sourced from two batches manufactured for commercial use in Hungary. Within each batch a total of 175 cartons, each containing 200 cigarettes, were sampled for use in the study.

\section{Measurement of ISO 'tar' and nicotine yields in smoke and cigarette physical parameters}

For each batch of study cigarettes, the 'tar' and nicotine yields in smoke were determined according to ISO methods (23-26). Five cigarettes per port were smoked through five ports on a SM450 linear smoking machine (Cerulean, Milton Keynes, UK) and the mainstream smoke was collected onto 44-mm Cambridge filter pads.

The Cambridge filter pads were extracted in $20 \mathrm{~mL}$ of propan-2-ol containing the internal standards $0.25 \mathrm{mg} / \mathrm{mL} n$ heptadecane for the determination of nicotine, and $5 \mathrm{~mL} / \mathrm{L}$ ethanol for the determination of water. The extract was analysed by gas chromatography (GC) by injection of each sample into two injection ports connected to two analytical columns. A CP Wax $52 \mathrm{CB}, 25 \mathrm{~m} \times 0.53 \mathrm{~mm} \times 2 \mu \mathrm{m}$, column and flame ionisation detector (FID) were used for the analysis of the nicotine. A $10 \mathrm{~m} \times 0.53 \mathrm{~mm}$ column containing PoroPlot $\mathrm{Q}$ and a thermal conductivity detector (TCD) were used for water analysis (6890 GC System, Agilent, Wokingham, UK). This procedure was conducted nine times for each batch using cigarettes, each time from a different carton. Measurements were also made of cigarette circumference, weight, pressure drop and filter ventilation with a QTM6 (Cerulean, Milton Keynes, UK). 


\section{Subjects}

Smokers of the 1-mg product were recruited by MASMI market research agency (MRA) in Hungary. The composition of each group was as far as possible representative of the demographics of the product's smokers in Hungary. They were separated into three groups (A, $\mathrm{n}=70 ; \mathrm{B}, \mathrm{n}=70 ; \mathrm{C}, \mathrm{n}=68)$.

Eligible subjects were aged between 18 and 64 years and self-reported average consumption as being at least ten cigarettes per day and had been smoking the product for at least six months. Women were excluded if they reported they were pregnant. The subjects who passed the screening criteria were briefed on the study protocol before giving their written informed consent to participate.

\section{Protocol for smoking repeats}

The three groups of smokers all smoked cigarettes from Batch 1, then Batch 2 on three separate occasions per batch (smoking repeats).

The subjects were visited at home by MRA staff twice a week for 6-8 weeks. In week 1 (repeat 1) each subject was provided with a minimum of two packs of test product from the first batch and a filter cutter and collector (20). The subjects were asked to smoke the cigarettes as usual in their everyday environment and to cut and collect a minimum of fifteen $10 \pm 1 \mathrm{~mm}$ sections from the mouth end of the filters of their spent cigarettes. This number of filters enables three independent replicates for analysis (5) and has been shown to be sufficient to provide an estimate of average MLE to 'tar' and nicotine per cigarette (27). Once the subjects had finished the study cigarettes they were asked to return to smoking their own purchased cigarettes for the rest of the week. In week 2 MRA staff visited the subjects' homes to collect the cut filters and to provide the study product for the second smoking repeat and a new filter cutter and collector. This process was repeated until each subject had smoked study cigarettes from Batch 1 and Batch 2 three times.

\section{Filter analysis}

MLE to 'tar' and nicotine was assessed using the part-filter analysis method (5). The method involves the collection of the filters from the cigarettes smoked by the subjects in their everyday environment, and the analysis of the amounts of 'tar' and nicotine retained in $10 \mathrm{~mm}$ mouth-end sections of the filters. The amounts of nicotine retained within the part-filters were measured directly as nicotine, but the amounts of 'tar' retained within the part-filters were measured indirectly as UV absorbance of the materials extracted from the filters.

Calibration values were produced by machine smoking five cigarettes from each batch onto a $44 \mathrm{~mm}$ Cambridge filter pad with a Borgwaldt RM20 CSR smoking machine (Borgwaldt KC, Hamburg, Germany). Six smoking regimes covering a wide range of typical human smoking behaviour parameters were used (5). This procedure was duplicated on a different day to provide independent replicate data. Two sets of unsmoked filters were also included. The Cambridge filter pads were extracted and analysed for 'tar', nicotine and water content as for the measurement of ISO 'tar' and nicotine yields.

Tip data for nicotine and 'tar' for cigarettes smoked by machine for calibration and by smokers were obtained by analysis of the $10 \mathrm{~mm}$ part filters. The part filters were measured to the nearest $0.1 \mathrm{~mm}$ before being extracted with methanol incorporating $0.05 \mathrm{mg} / \mathrm{mL} n$-heptadecane as an internal standard. Nicotine content was analysed by GC with FID detection and analytical column, CP Wax $52 \mathrm{CB}$, $25 \mathrm{~m} \times 0.53 \mathrm{~mm} \times 2.0 \mu \mathrm{m}$ film $(6890 \mathrm{GC}$ System, Agilent, Wokingham, UK). The 'tar' content was determined from the extracts using a UV absorbance method (high performance liquid chromatography with UV detection at $310 \mathrm{~nm}$ ). Full details of these procedures are described by ST CHARLES et al. (5).

MLE to nicotine for smokers was assessed with the linear regression equation obtained by plotting the mainstream smoke nicotine yield versus the tip nicotine data obtained during calibration smoking (and from the unsmoked filters, in which case the yield was set to zero) and the measured smoker tip nicotine values. Similarly, MLE to 'tar' was obtained with the linear regression equation derived by plotting mainstream smoke nicotine free dry particulate matter (i.e., 'tar' yield), versus UV absorbance per tip obtained during calibration smoking (and unsmoked filters) and the measured smoker tip UV absorbance data.

\section{Intermediate precision in the construction of calibration curves}

To investigate the intermediate precision (22) of using different smoking machines and operators in the construction of the calibration curves, additional calibration smoking was conducted with cigarettes from Batch 1, three Borgwaldt RM20 CSR smoking machines and three operators. Each operator produced two calibrations comprising the six calibration regimes and unsmoked filters (5), on each of the three smoking machines. Machine smoking according to each regime was performed twice, on different days, to provide independent replicate data. Where data were missing, no repeats were conducted. The measurement of mainstream and tip nicotine and 'tar' were conducted as described above.

The data from the additional calibrations were used to produce 18 (three machines $\times$ three operators $\times$ two calibrations) mainstream smoke 'tar' versus UV absorbance per tip and mainstream smoke nicotine versus tip nicotine calibration plots.

\section{Data analysis}

Minitab 16 statistical software was used to analyse the data. All data are presented as mean \pm standard deviation (SD). Within each batch, ANOVA general linear model (ANOVA GLM) was used to compare the MLE to 'tar' and nicotine of the three smoker groups with the smoking repeats MLE nested within smoker groups. Within each group the subjects were aligned and the Pearson correlation was calculated for MLE to 'tar' and nicotine obtained for the three repeats (1 versus 2, 2 versus 3, 1 versus 3 ). ANOVA GLM with subject as random factor (paired t-test) was used to compare the MLE to 'tar' and nicotine from the 
Table 1. ISO machine smoking and physical characteristics.

\begin{tabular}{l|c|c}
\hline \multirow{2}{*}{ Result parameter } & Batch 1 & Batch 2 \\
\cline { 2 - 3 } & \multicolumn{2}{|c}{ Mean (Standard deviation) } \\
\hline \multicolumn{3}{|c}{$\begin{array}{l}\text { Machine smoking (ISO): 9 } \\
\text { replicate }\end{array}$} \\
'Tar' (mg/cig) & \multicolumn{2}{c}{} \\
Nicotine (mg/cig) & $1.6 \pm 0.1$ & $1.6 \pm 0.2$ \\
CO (mg/cig) & $0.13 \pm 0.01$ & $0.14 \pm 0.01$ \\
Puff number & $2.3 \pm 0.1$ & $2.2 \pm 0.1$ \\
Physical measurements: 9 replicates, 20 cigarettes per \\
replicate & $7.6 \pm 0.2$ & $7.7 \pm 0.2$ \\
Circumference (mm) & $24.6 \pm 0.01$ & $24.6 \pm 0.03$ \\
Filter ventilation (\%) & $73.7 \pm 0.5$ & $73.6 \pm 0.7$ \\
Pressure drop (mm WG) & $91.6 \pm 0.7$ & $90.3 \pm 1.0$ \\
Weight (mg) & $920 \pm 3$ & $910 \pm 8$ \\
\hline
\end{tabular}

a mm water gauge

two cigarette batches. To assess the influence of smoking machine and operator on the 18 additional calibration curves the regression data (slopes and intercepts) were compared using ANOVA GLM.

\section{RESULTS}

\section{Characteristics of cigarettes and subjects}

Table 1 contains the mean results of the ISO (23-26) machine smoking and cigarette physical measurements. The mean results obtained from Batch 1 and 2 cigarettes were within $10 \%$ of each other for all measurements, which indicates that the cigarette batches were well matched. The 208 subjects enrolled were well matched across the three groups in terms of gender, age, education and geographical location distributions (Table 2).

\section{Part-filter calibration smoking results}

The slopes and intercepts for 'tar' and nicotine obtained during calibration machine smoking did not differ significantly between cigarettes in Batch 1 and Batch 2 (for nicotine yield the $\mathrm{p}$ values for slope and intercept were $\mathrm{p}=$ 0.050 and $p=0.994$, respectively, and for ' $\operatorname{tar}$ ' yield they were $p=0.126$ and $p=0.849$, respectively; Table 3 ). The two batches were well matched in terms of physical and smoke yield measurements (Table 1), but differed slightly for filter efficiency. The cigarettes from Batch 2 retained more nicotine and 'tar' in the filter than did those in Batch 1, although they yielded similar amounts of nicotine and 'tar' for a given smoking regime. Thus, an observable, although non-significant, difference from the slopes obtained for the calibration was noted. The use of batchspecific calibrations compensated for the higher levels of nicotine and 'tar' retained in the human smoked filters from Batch 2 cigarettes, highlighting the importance of conducting a calibration for each study product (5).

\section{Repeatability of MLE to 'tar' and nicotine}

Mean MLE to 'tar' did not differ significantly between the three groups of subjects, $p=0.509$ for Batch 1 cigarettes, and $\mathrm{p}=0.352$ for Batch 2 cigarettes; or nicotine MLE, $p=0.102$ for Batch 1 cigarettes and $p=0.218$ for Batch 2 cigarettes (Table 4). This finding indicates a high degree of repeatability of MLE to 'tar' and nicotine when different groups of well-matched subjects smoke the same cigarette type. Within groups there were no significant differences in mean MLE to 'tar' or nicotine between smoking repeats (Table 4). Additionally, highly significant correlations $(p<0.001)$ were seen for smoking repeats within groups, with the $r$ values for 'tar' falling within the range of 0.731-0.919 and those for nicotine falling within the range of 0.709-0.920 (Table 4). These results indicate a high degree of repeatability in MLE to 'tar' and nicotine when the same subjects smoke the same type of cigarette on repeated occasions.

\section{Effect of cigarette batch on smokers' MLE to 'tar' and nicotine}

MLE to 'tar' and nicotine was assessed in 208 subjects, separated into three groups (Table 2). All subjects were asked to smoke cigarettes from the two batches of study cigarettes. Not all smokers completed all smoking repeats and, therefore, MLE comparisons were based on 619 and 609 smoking repeats in cigarette Batch 1 and 2, respectively. The mean MLE to 'tar' and nicotine was marginally but significantly higher for cigarette Batch 1 than for Batch 2 ('tar': $9.4 \pm$ $3.3 \mathrm{mg} / \mathrm{cig}$ versus $9.0 \pm 3.7 \mathrm{mg} / \mathrm{cig}, \mathrm{p}<0.001$; nicotine: 0.84 $\pm 0.29 \mathrm{mg} / \mathrm{cig}$ versus $0.82 \pm 0.33 \mathrm{mg} / \mathrm{cig}, \mathrm{p}=0.003)$. The paired data and the high number of measurements enabled discrimination of a small bias, but had these data been treated independently they would not be significantly different.

Intermediate precision in construction of the calibration curves

Comparison of the slopes and intercepts for the three different operators and three different machines did not

Table 2. Subject demographic data.

\begin{tabular}{ll|c|c|c}
\hline \multicolumn{2}{l|}{ Demographic profile } & $\begin{array}{c}\text { Group } \\
\text { A }\end{array}$ & $\begin{array}{c}\text { Group } \\
\text { B }\end{array}$ & $\begin{array}{c}\text { Group } \\
\text { C }\end{array}$ \\
\hline Category & Description & \multicolumn{3}{|c}{ Number } \\
\hline Total & Smokers & 70 & 70 & 68 \\
Gender & Male & 26 & 26 & 24 \\
& Female & 44 & 44 & 44 \\
Age group & $18-29$ & 21 & 20 & 22 \\
& $30-39$ & 20 & 18 & 18 \\
& $40-49$ & 11 & 11 & 11 \\
Education & P0-64 & 18 & 21 & 17 \\
& Primary/vocational & 17 & 22 & 24 \\
& Secondary & 36 & 32 & 30 \\
City & University & 17 & 16 & 14 \\
& Budapest & 39 & 37 & 39 \\
& Other cities & 31 & 33 & 29 \\
\hline
\end{tabular}


Table 3. Calibration smoking results.

\begin{tabular}{l|ccc|c|c|c}
\hline \multirow{2}{*}{ Cigarette batch } & \multicolumn{3}{|c|}{ Nicotine yield versus tip nicotine } & \multicolumn{3}{c}{ 'Tar' yield versus tip UV absorbance } \\
\cline { 2 - 7 } & Slope & Intercept & $\mathrm{R}^{2}(\%)$ & Slope & Intercept & $\mathrm{R}^{2}(\%)$ \\
\hline \multirow{2}{*}{1} & 6.39 & -0.058 & 98.1 & 0.0424 & -0.72 & 98.5 \\
2 & 5.71 & -0.058 & 98.4 & 0.0391 & -0.65 & 98.5 \\
\hline
\end{tabular}

differ significantly at the $95 \%$ confidence level for ' $t a r$ ' versus tip UV absorbance (intercept, $\mathrm{p}=1.000$; slope, $\mathrm{p}=0.856$ ) or nicotine yield versus tip nicotine (intercept, $\mathrm{p}=1.000$, slope; $\mathrm{p}=0.980 ;$ Table 5). These findings indicate that the part-filter method can provide robust results when calibration smoking is conducted by different operators and on different smoking machines.

\section{DISCUSSION}

We have shown that part-filter analysis is a robust way to measure MLE in different groups of smokers and over smoking repeats. It has been shown previously that the part-filter analysis methodology is sensitive enough to compare different groups of smokers smoking their own products within a market $(17-19,33)$ and across markets (16) and the same group of smokers smoking different products (3). However, the method must display some stability to provide integrity of the results and in our systematic study we ensured that the subjects enrolled were well matched for gender, age, education and geographical location. This was a critical aspect of the study, as MLE to ' $\operatorname{tar}$ ' and nicotine may be influenced by demographic factors. For example, male smokers tend to have higher MLE values than female smokers $(16,17)$, owing primarily to average higher puff volumes (27-30).

Our findings indicate a high degree of repeatability in MLE to 'tar' and nicotine in different well-matched groups smoking the same cigarette type. This observation is

Table 4: Comparison of MLE to 'tar' and nicotine, by smoker group.

\begin{tabular}{|c|c|c|c|c|c|c|c|}
\hline \multirow{3}{*}{ Cigarette batch } & \multirow{3}{*}{ Smoker group } & \multicolumn{3}{|c|}{ MLE mean \pm SD } & \multicolumn{3}{|c|}{$r^{c}$} \\
\hline & & \multicolumn{3}{|c|}{ Repeat smoking } & \multicolumn{3}{|c|}{ Correlation between repeats } \\
\hline & & 1 & 2 & 3 & 1 and 2 & 1 and 3 & 2 and 3 \\
\hline \multicolumn{8}{|l|}{ ‘Tar' (mg/cig) } \\
\hline \multirow[t]{5}{*}{1} & $A$ & $9.7 \pm 3.2$ & $9.3 \pm 3.4$ & $9.7 \pm 3.6$ & 0.894 & 0.875 & 0.907 \\
\hline & $B$ & $9.4 \pm 3.3$ & $9.5 \pm 3.4$ & $9.3 \pm 3.8$ & 0.874 & 0.731 & 0.861 \\
\hline & $\mathrm{C}$ & $9.3 \pm 2.9$ & $9.2 \pm 3.1$ & $9.1 \pm 3.2$ & 0.903 & 0.898 & 0.890 \\
\hline & $p=0.509^{a}$ & & & & - & - & - \\
\hline & $p=0.993^{b}$ & & & & - & - & - \\
\hline \multirow[t]{5}{*}{2} & $A$ & $9.1 \pm 3.7$ & $9.4 \pm 4.0$ & $9.3 \pm 4.1$ & 0.918 & 0.895 & 0.900 \\
\hline & B & $8.5 \pm 3.3$ & $9.1 \pm 3.9$ & $9.2 \pm 3.7$ & 0.898 & 0.831 & 0.904 \\
\hline & $\mathrm{C}$ & $8.6 \pm 3.0$ & $8.7 \pm 3.7$ & $9.0 \pm 3.6$ & 0.919 & 0.887 & 0.902 \\
\hline & $p=0.352^{a}$ & & & & - & - & - \\
\hline & $p=0.917^{b}$ & & & & - & - & - \\
\hline \multicolumn{8}{|l|}{ Nicotine (mg/cig) } \\
\hline \multirow[t]{5}{*}{1} & A & $0.88 \pm 0.28$ & $0.86 \pm 0.30$ & $0.88 \pm 0.33$ & 0.885 & 0.880 & 0.902 \\
\hline & $B$ & $0.86 \pm 0.30$ & $0.72 \pm 0.24$ & $0.86 \pm 0.34$ & 0.844 & 0.709 & 0.851 \\
\hline & C & $0.86 \pm 0.25$ & $0.84 \pm 0.28$ & $0.84 \pm 0.29$ & 0.915 & 0.890 & 0.890 \\
\hline & $p=0.102^{a}$ & & & & - & - & - \\
\hline & $p=0.125^{b}$ & & & & - & - & - \\
\hline \multirow[t]{5}{*}{2} & $A$ & $0.83 \pm 0.34$ & $0.86 \pm 0.37$ & $0.87 \pm 0.37$ & 0.908 & 0.888 & 0.912 \\
\hline & B & $0.77 \pm 0.29$ & $0.83 \pm 0.35$ & $0.84 \pm 0.30$ & 0.914 & 0.832 & 0.872 \\
\hline & $\mathrm{C}$ & $0.77 \pm 0.28$ & $0.79 \pm 0.33$ & $0.82 \pm 0.32$ & 0.920 & 0.895 & 0.904 \\
\hline & $p=0.218^{a}$ & & & & - & - & - \\
\hline & $p=0.793^{b}$ & & & & - & - & - \\
\hline
\end{tabular}

a ANOVA GLM, smoker group, $\mathrm{n}=3$

b ANOVA GLM, repeat smoke nested within smoker group, $n=9$

c Pearson correlation of repeats within a group ( $p$ value), $n=3$, for all values: $(p<0.001)$; 
Table 5. Slopes and intercepts for additional calibration data.

\begin{tabular}{|c|c|c|c|c|c|}
\hline \multirow{2}{*}{ Smoking machine } & \multirow{2}{*}{ Operator } & \multicolumn{2}{|c|}{ 'Tar' versus tip UV absorbance } & \multicolumn{2}{|c|}{ Nicotine yield versus tip nicotine } \\
\hline & & Slope & Intercept & Slope & Intercept \\
\hline \multicolumn{6}{|l|}{ Calibration 1} \\
\hline \multirow[t]{3}{*}{1} & 1 & 0.0372 & -0.67 & 6.20 & -0.072 \\
\hline & 2 & 0.0349 & -0.55 & 6.38 & -0.071 \\
\hline & 3 & 0.0362 & -0.55 & 6.38 & -0.074 \\
\hline \multirow[t]{3}{*}{2} & 1 & 0.0354 & -0.57 & 6.13 & -0.066 \\
\hline & 2 & 0.0316 & -0.32 & 5.83 & -0.045 \\
\hline & 3 & 0.0362 & -0.56 & 6.23 & -0.062 \\
\hline \multirow[t]{3}{*}{3} & 1 & 0.0361 & -0.47 & 6.21 & -0.052 \\
\hline & 2 & 0.0371 & -0.46 & 6.35 & -0.047 \\
\hline & 3 & 0.0376 & -0.29 & 6.31 & -0.034 \\
\hline \multicolumn{6}{|l|}{ Calibration 2} \\
\hline \multirow[t]{3}{*}{1} & 1 & 0.0360 & -0.47 & 5.97 & -0.055 \\
\hline & 2 & 0.0361 & -0.66 & 6.12 & -0.064 \\
\hline & 3 & 0.0349 & -0.44 & 5.87 & -0.051 \\
\hline \multirow[t]{3}{*}{2} & 1 & 0.0351 & -0.55 & 6.12 & -0.075 \\
\hline & 2 & 0.0367 & -0.65 & 6.13 & -0.068 \\
\hline & 3 & 0.0371 & -0.52 & 6.17 & -0.065 \\
\hline \multirow[t]{3}{*}{3} & 1 & 0.0366 & -0.45 & 6.14 & -0.052 \\
\hline & 2 & 0.0354 & -0.40 & 6.06 & -0.056 \\
\hline & 3 & 0.0364 & -0.55 & 6.02 & -0.032 \\
\hline
\end{tabular}

consistent with the findings reported by NELSON and colleagues (17). In their study, conducted with US smokers, very small differences $(<6 \%)$ were noted in mean 'tar' and nicotine MLE per cigarette between two demographically matched groups of 157 US subjects smoking their usual brands of cigarettes.

Individual smokers exhibit a wide range of smoking behaviour $(2-4,7,16-21,33)$ and MLE from smokers' individual cigarettes will vary $(27,32)$. It has been shown that 15 part filters collected from an individual smoker over $24 \mathrm{~h}$ is sufficient to obtain a representative estimate of mean MLE per cigarette (27). Therefore on average, smokers tend to maintain their puffing behaviour when smoking cigarettes of the same type.

Our findings indicate a high level of repeatability within smoker groups smoking the same cigarette type. This is consistent with NELSON and colleagues (17) who reported statistically significant correlations $(p<0.001)$ for MLE to nicotine and 'tar' for a group of 157 US subjects smoking their usual brand of cigarettes on two occasions separated by a two week interval.

The mean MLE values for 'tar' and nicotine are higher than those reported in some previous part-filter studies of 1-mg ISO machine yield cigarettes. MARINER et al. (16) showed means of $7.8 \mathrm{mg} / \mathrm{cig}$ 'tar', $0.77 \mathrm{mg} / \mathrm{cig}$ nicotine for smokers in an eight-country survey. ST CHARLES et al. (18) showed means of $5.0-6.5 \mathrm{mg} / \mathrm{cig}$ 'tar', $0.41-0.54 \mathrm{mg} / \mathrm{cig}$ nicotine in US smokers, and CôTÉ et al. (21) showed means of $6.1 \mathrm{mg} / \mathrm{cig}$ 'tar', $0.67 \mathrm{mg} / \mathrm{cig}$ nicotine in Canadian smokers. Our mean MLE value for 'tar' was also higher than the value reported by NELSON and colleagues (17) (mean of $7.7 \mathrm{mg} / \mathrm{cig}$ ) for smokers of US 1-mg 'tar' yield cigarettes, but the mean nicotine value of $0.85 \mathrm{mg} / \mathrm{cig}$ they reported was similar to that in our study. By contrast with the other studies, MLE data obtained for both 'tar' and nicotine from two groups of 1-mg ISO 'tar' smokers in Russia showed agreement (mean 'tar' 8.9 and $9.4 \mathrm{mg} / \mathrm{cig}$, mean nicotine 0.98 and $0.86 \mathrm{mg} / \mathrm{cig}$ ) (33). The differences in mean MLE values obtained from the smokers in this study and those obtained from the previous published studies may be attributed to several factors, including possible differences in smoker' behaviours and cigarette design features.

\section{CONCLUSION}

Our assessment provides robust evidence that when calibration smoking is conducted by different operators and on different smoking machines, the results remain consistent. Previous studies have confined the calibration smoking of each study product to one smoking machine and one operator $(2,16,19-21)$. Our findings, however, indicate that the technique could be applied to large-scale studies of smokers where the employment of multiple operators and smoking machines within a laboratory would be necessary.

We conclude that the part-filter analysis method offers a relatively simple, non-invasive and repeatable means of estimating MLE to 'tar' and nicotine in large-scale studies of smokers in their normal smoking environments.

\section{COMPETING INTERESTS}

This work was funded by British American Tobacco (BAT), and all authors, with the exception of Dr Mike Dixon are full time employees of BAT. Dr Mike Dixon's involvement was in the capacity of a paid consultant to BAT. 


\section{AUTHORS' CONTRIBUTIONS}

K.P. designed and conducted the study. M.A. and K.P. conducted statistical analysis. All authors were involved in data interpretation. M.A. and M.D. wrote the main manuscript text. M.A. prepared the Tables. All authors reviewed the manuscript.

\section{REFERENCES}

1. Shepperd, C.J., F.K. St Charles, M. Lien, and M. Dixon: Validation of Methods for Determining Consumer Smoked Cigarette Yields from Cigarette Filter Analysis; Beitr. Tabakforsch. Int. 22 (2006) 176-184.

2. Shepperd, C.J., A.C. Eldridge, D.C. Mariner, M. McEwan, G. Errington, and M. Dixon: A Study to Estimate and Correlate Cigarette Smoke Exposure in Smokers in Germany as Determined by Filter Analysis and Biomarkers of Exposure; Regul. Toxicol. Pharmacol. 55 (2009) 97-109.

3. Shepperd, C.J., A.C. Eldridge, G. Errington, and M. Dixon: A Study to Evaluate the Effect of Mouth Level Exposure and Biomarkers of Exposure Estimates of Cigarette Smoke Exposure Following A Forced Switch to a Lower ISO 'Tar' Yield Cigarette; Regul. Toxicol. Pharmacol. 61 (2011) S13-S24.

4. Morin, A., C.J. Shepperd, A.C. Eldridge, N. Poirier, and R. Voisine: Estimation and Correlation of Cigarette Smoke Exposure in Canadian Smokers as Determined by Filter Analysis and Biomarkers of Exposure; Regul. Toxicol. Pharmacol. 61 (2011) S3-S12.

5. St Charles, F.K., M. Ashley, C.J. Shepperd, P. Clayton, and G. Errington: A Robust Method for Estimating Human Smoked Cigarette Yields From Filter Analysis Data; Beitr. Tabakforsch. Int. 23 (2009) 232-243.

6. Polzin, G.M., W. Wu, X. Yan, J.M. McCraw, S. AbdulSalaam, A.D. Tavakoli, L. Zhang, D.L. Ashley, and C.H. Watson: Estimating Smokers' Mouth Level Exposures to Select Mainstream Smoke Constituents From Discarded Cigarette Filter Butts; Nicotine Tob. Res. 11 (2009) 868-874.

7. Ashley, D.L., R.J. O' Connor, J.T. Bernert, C.H. Watson, G.M. Polzin, R.B. Jain, D. Hammond, D.K. Hatsukami, G.A. Giovino, K.M. Cummings, A. McNeill, L. Shahab, B. King, G.T. Fong, L. Zhang, Y. Xia, X. Yan, and J.M. McCraw: Effect of Differing Levels of Tobacco-Specific Nitrosamines in Cigarette Smoke on the Levels of Biomarkers in Smokers; Cancer Epidemiol. Biomarkers Prev. 19 (2010) 1389-1398.

8. Moldoveanu S.C. and F.K. St Charles: Differences in the Chemical Composition of the Particulate Phase of Inhaled and Exhaled Cigarette Mainstream Smoke; Beitr. Tabakforsch. Int. 22 (2007) 290-302.

9. Moldoveanu, S.C., W.M. Coleman III, and J.M. Wilkins: Determination of Carbonyl Compounds in Exhaled Cigarette Smoke; Beitr. Tabakforsch. Int. 22 (2007) 346-357.
10. Moldoveanu, S.C., W.M. Coleman III, and J.M. Wilkins: Determination of Polycyclic Aromatic Hydrocarbons in Exhaled Cigarette Smoke; Beitr. Tabakforsch. Int. 23 (2008) 85-97.

11. Moldoveanu, S.C., W.M. Coleman III, and J.M. Wilkins: Determination of Hydroxybenzenes in Exhaled Cigarette Smoke; Beitr. Tabakforsch. Int. 23 (2008) 98-106.

12. Moldoveanu, S.C., W.M. Coleman III, and J.M. Wilkins: Determination of Benzene and Toluene in Exhaled Cigarette Smoke; Beitr. Tabakforsch. Int. 23 (2008) 107-114.

13. Moldoveanu, S.C. and W.M. Coleman III: The Influence of a Humectant on the Retention by Humans of Solanesol From Cigarette Smoke Part 1, Propylene Glycol; Beitr. Tabakforsch. Int. 23 (2008) 153-159.

14. Moldoveanu, S.C. and W.M. Coleman III: A Pilot Study to Assess Solanesol Levels in Exhaled Cigarette Smoke; Beitr. Tabakforsch. Int. 23 (2008) 144-152.

15. Moldoveanu, S.C. and W.M. Coleman III: The Influence of a Humectant on the Retention by Humans of Solanesol From Cigarette Smoke (Part 2, Glycerin); Beitr. Tabakforsch. Int. 23 (2009) 377-383.

16. Mariner, D.C., M. Ashley, C.J. Shepperd, G. Mullard, and M. Dixon: Mouth Level Exposure Using Analysis of Filters From Smoked Cigarettes: A Study of Eight Countries; Regul. Toxicol. Pharmacol. 61 (2011) S39-S50.

17. Nelson, P.R., P. Chen, M. Dixon, and T. Steichen: A Survey of Mouth Level Exposure to Cigarette Smoke in the US; Regul. Toxicol. Pharmacol. 61 (2011) S25-S38.

18. St Charles, F.K., A.A. Kabbani, and M.F. Borgerding: Estimating 'Tar' and Nicotine Exposure: Human Smoking Versus Machine Smoking; Regul. Toxicol. Pharmacol. 56 (2010) 100-110.

19. Ashley, M., A. Sisodiya, M. McEwan, J. McAughey, and K. Prasad: Comparison of Mouth Level Exposure to 'Tar' and Nicotine in Smokers of Normal and Superslim King Size Cigarettes in Romania; Beitr. Tabakforsch. Int. 24 (2011) 277-288.

20. Ashley, M., P. Saunders, G. Mullard, K. Prasad, D. Mariner, J. Williamson, and A. Richter: Smoking Intensity Before and After Introduction of the Public Place Smoking Ban in Scotland; Regul. Toxicol. Pharmacol. 61 (2011) S60-S65.

21. Côté, F., C. Létourneau, G. Mullard, and R. Voisine: Estimation of Nicotine and 'Tar' Yields From HumanSmoked Cigarettes Before and After the Implementation of the Cigarette Ignition Propensity Regulations in Canada; Regul. Toxicol. Pharmacol. 61 (2011) S51-S59.

22. International Conference on Harmonisation (ICH): Validation of Analytical Procedures: Text and Methodology Q2(R1);1994, Available at: http://www.ich. org/fileadmin/Public_Web_Site/ICH Products/Guidelines/Quality/Q2_R1/Step4/Q2_R1_ Guideline.pdf. (Accessed 27 May 2015).

23. International Organization for Standardization (ISO): International Standard 10362-1:1999. Cigarettes Determination of Water in Smoke Condensates - Part 1: 
Gas-Chromatographic Method; ISO, Geneva, Switzerland, 1999.

24. International Organization for Standardization (ISO): International Standard 3308:2000. Routine Analytical Smoking Machine - Definition and Standard Condition; ISO, Geneva, Switzerland, 2000.

25. International Organization for Standardization (ISO): International Standard 4387:2000. Cigarettes - Determination of Total and Nicotine Free Dry Particulate Matter Using A Routine Analytical Smoking Machine; ISO, Geneva, Switzerland, 2000.

26. International Organization for Standardization (ISO) International Standard 10315:2000. Cigarettes - Determination of Nicotine in Smoke Condensates - GasChromatographic Method; ISO, Geneva, Switzerland, 2000.

27. Mariner, D.C., A. Sisodiya, and S.K. Prasad: Cigaretteto-Cigarette Variation in Smoking Intensity Over a 24 Hour Period; Poster Presentation POS1-10, SRNT Europe (2008), 10th Annual Meeting, Rome, available at: http://www.pipistrelle-test.com/groupms/sites/BAT 7AWFH3.nsf/vwPagesWebLive/DO83DJV8/\$FILE/ CORESTA\%202009\%20SSPTPOST16\%20Mariner $\% 20 \mathrm{et} \% 20 \mathrm{al} \% 2024 \mathrm{hr} \% 20$ variation.pdf?openelement (Accessed 27 May 2015).

28. Bättig, K., R. Buzzi, and R. Nil: Smoke Yield of Cigarettes and Puffing Behavior in Men and Women; Psychopharmacology 76 (1982) 139-148.

29. Höfer, I., R. Nil, K. Bättig: Nicotine Yield as a Determinant of Smoke Exposure Indicators and Puffing Behavior; Pharmacol. Biochem. Behav. 40 (1991) 139-149.
30. Hee, J., F. Callais, I. Mormas, A.M. Laurent, S. Min, P. Molinier, M. Chastagnier, J.R. Claude, B. Festy: Smokers' Behaviour and Exposure According to Cigarette Yield and Smoking Experience; Pharmacol. Biochem. Behav. 52 (1995) 195-203.

31. Eissenberg, T., C. Adams, E.C. Riggins 3rd, and M. Likness: Smokers' Sex and the Effects of Tobacco Cigarettes: Subject-Rated and Physiological Measures; Nicotine Tob. Res. 1 (1999) 317-324.

32. Grainge, M.J., L. Shahab, D. Hammond, R.J. O' Connor, and A. McNeill: First Cigarette on Waking and Time of Day as Predictors of Puffing Behaviour in UK Adult Smokers; Drug Alcohol Depend. 101 (2009) 191-195.

33. Ashley, M., M. Dixon, and K. Prasad: Relationship Between Cigarette Format and Mouth-Level Exposure to 'Tar' and Nicotine in Smokers of Russian King-Size Cigarettes; Regul. Toxicol. Pharmacol. 70 (2014) 430-437.

Corresponding author:

Madeleine Ashley

British American Tobacco

Group Research and Development

Southampton SO15 8TL, UK

E-mail: madeleine_ashley@bat.com 